\title{
Current concepts in the treatment of intra-articular calcaneal fractures: results of a nationwide survey
}

\author{
T. Schepers • E. M. M. van Lieshout • \\ T. M. van Ginhoven • M. J. Heetveld • P. Patka
}

Received: 14 March 2007 /Revised: 31 March 2007 / Accepted: 13 April 2007 / Published online: 13 June 2007

(C) Springer-Verlag 2007

\begin{abstract}
The treatment of intra-articular calcaneal fractures is controversial and randomised clinical trials are scarce. Moreover, the socio-economic cost remains unclear. The aim of this study was to estimate the incidence, treatment preferences and socio-economic cost of this complex fracture in the Netherlands. This data may aid in planning future clinical trials and support education. The method of study was of a cross-sectional survey design. A written survey was sent to one representative of both the traumatology and the orthopaedic staff in each hospital in the Netherlands. Data on incidence, treatment modalities, complications and follow-up strategies were recorded. The socio-economic cost was calculated. The average response rate was $70 \%$. Fracture classifications, mostly by Sanders and Essex-Lopresti, were applied by $29 \%$. Annually, 920 intra-articular calcaneal fractures $(0.4 \%$ incidence rate) were treated, mainly with ORIF (46\%), conservative $(39 \%)$ and percutaneous $(10 \%)$ treatment. The average non-weight-bearing mobilisation was 9 weeks (SD 2 weeks). An outcome score, mainly AOFAS, was
\end{abstract}

T. Schepers $(\bowtie) \cdot$ E. M. M. van Lieshout • T. M. van Ginhoven • M. J. Heetveld P. Patka

Department of Surgery-Traumatology, Erasmus MC, University

Medical Centre Rotterdam,

Room H9-74,

P.O. Box 2040,

3000 CA Rotterdam, The Netherlands

e-mail: t.schepers@erasmusmc.nl

M. J. Heetveld

Department of Surgery, Kennemer Gasthuis,

P.O. Box 417,

2000 AK Haarlem, The Netherlands documented by $7 \%$. A secondary arthrodesis was performed in $21 \%$ of patients. The socio-economic cost was estimated to be €21.5-30.7 million. Dutch intra-articular calcaneal fracture incidence is at least $0.4 \%$ of all fractures presenting to hospitals. Better insight into treatment modalities currently employed and costs in the Netherlands was obtained.

Résumé Le traitement des fractures articulaires du calcanéum reste controversé. Par ailleurs les aspects de coûts d'évaluation socio-économique ne sont pas très clairement connus. Le but de cette étude est d'évaluer leur incidence et d'envisager le meilleur traitement ainsi que les répercutions économiques de cette fracture complexe aux Pays-Bas. Un modèle d'étude a été envoyé à chaque responsable de service d'orthopédie traumatologie de chaque hôpital des Pays-Bas avec une évaluation de données comportant des modalités thérapeutiques, des complications, de suivi, de même que coûts socio-économiques. Résultats : le taux de réponse a été de $70 \%$. Les fractures ont été classées selon Sanders et Essex-Lopresti dans 29\% des cas. 920 fractures articulaires du calcanéum ont été traitées en une année $(0.4 \%)$, plus souvent avec ostéosynthèse interne $(46 \%)$, traitement conservateur $(39 \%)$, ou percutané $(10 \%)$. En moyenne, la reprise d'appui a été de 9 semaines. L'évaluation des résultats a été documentée dans $7 \%$ des cas selon le score AOFAS. Une arthrodèse secondaire a été réalisée chez $21 \%$ des patients et le coût socio-économique était estimé de 21.5 à 30.7 millions d'euros. En conclusion : l'incidence des fractures articulaires du calcanéum au PaysBas est d'au moins $0.4 \%$. De toutes les fractures traitées dans tous les hôpitaux néerlandais nous avons pu ainsi obtenir les éléments de ces fractures ainsi que leurs coûts. 


\section{Introduction}

Since the 1950s, the frequency of calcaneal fractures has been presumed to be around $2 \%$ of all fractures presenting to emergency departments and the proportion of intra-articular calcaneal fractures with involvement of the posterior subtalar joint approximately $75 \%[3,7,12,16,20,21]$. Controversy on the treatment of this type of fracture remains, as several different operative and non-operative strategies exist $[4,9,12,13]$. Intra-articular fractures carry a high morbidity; $40-85 \%$ of patients return to work within 9 months but approximately $20 \%$ are not able to return to work within a year, rendering intra-articular calcaneal fractures costly on a socio-economic level $[5,6,19]$.

Determining the socio-economic cost of intra-articular calcaneal fractures in the Netherlands requires knowledge of the incidence and an overview of the treatment approaches used. In addition, these data may support education, provide the basis for a consistent treatment guideline and may aid in planning future clinical trials.

The objective of this study was to assess the number of intra-articular calcaneal fractures seen by trauma surgeons and orthopaedic surgeons annually in the Netherlands. The second aim was to identify surgeons' preferences in the treatment of calcaneal fractures. Based upon these data, the socioeconomic burden of this type of fracture was estimated.

\section{Methods}

A postal survey was developed according to the guidelines as provided by a meta-analysis of randomised studies of postal surveys to optimise response rates [11]. Attention was paid to the recommendations of the American Association for Public Opinion Research (AAPOR) [18]. Four trauma surgeons from a level-1 trauma centre aided in the development of the questionnaire. The questions included in the survey were derived from the existing literature on the subject and are shown in Table 1. The choice of treatment was limited to the six most frequently mentioned modalities in the literature: conservative treatment (functional and plaster of Paris), manual reduction, Essex-Lopresti manoeuvre, Forgon and Zadravecz (percutaneous) distraction technique, open reduction and internal fixation (ORIF), and primary arthrodesis. Morbidity registration was limited to compartment syndrome of the foot, wound dehiscence, superficial wound infection and deep infection (osteomyelitis and pin-track infection).

The survey was sent to one representative of the trauma surgery staff and one representative of the orthopaedic surgery staff in each hospital in the Netherlands. Recipients were selected by contacting all hospitals prior to the survey. The goals of the survey were explained in a personally addressed accompanying letter. A stamped returning envelope was provided.

A total of 274 surveys were sent to 137 hospitals. After three weeks, a reminder was sent, including a copy of the survey and a returning envelope.

To assess the incidence of intra-articular calcaneal fractures, the total number of patients with any type of fracture seen at the emergency departments in the Netherlands was retrieved from the Dutch Injury Information System (LIS, Letsel Informatie Systeem; http://www.veilig heid.nl). This number is an estimate, calculated by extrapolating the number of patients seen at 14 representative emergency departments in the Netherlands. In addition, the number of patients with a calcaneal fracture, both intraand extra-articular, admitted to the hospital was retrieved from the Dutch National Medical Registration (LMR, Landelijke Medische Registratie; http://www.prismant.nl). The LMR is a database in which diseases and injuries of hospital admissions are gathered and coded according to the International Classification of Diseases (ICD). The average number of patients admitted to the hospital from 2002 to

Table 1 Questions of the closed reduction vs. open reduction and internal fixation (ORIF) vs. non-operative study (CRONOS) of the displaced intra-articular calcaneal fractures (DIACF) survey

Questions of the CRONOS survey

1. Is your profession Trauma Surgeon or Orthopaedic Surgeon?

2. In what hospital are you currently employed?

3. How many new patients with a DIACF are treated in your hospital annually?

4. What fracture classification do you use?

5. What treatment modality do you use?

6. What type of osteosynthesis material do you apply? Do you use bone grafting? How many weeks do patients mobilise non-weight bearing?

7. How frequently do you encounter the following complications: compartment syndrome, superficial and deep infection, wound dehiscence?

8. Do you apply a standardised outcome score? If yes, which?

9. How many patients need a secondary arthrodesis?

10. How many patients return to work?

10. Would you consider participation in a RCT?

$\mathrm{RCT}=$ randomised controlled trial; DIACF=displaced intra-articular calcaneal fracture 
2004 with a calcaneal fracture was retrieved from this database.

\section{Analysis}

All of the data of the survey was gathered in a Microsoft Access database.

The socio-economic cost was calculated with the use of the "per patient costs," as determined by Brauer et al. [6]. In this Canadian study, the costs per patient treated conservatively or operatively were calculated on the basis of qualityadjusted life years (QALY), including the costs of a secondary arthrodeses, complication and time lost from work [6]. The average costs per patient treated operatively were CAN $\$ 32,000$ ( $€ 19,000$; benefit of 2.50 QALYs). For the non-operatively treated patients, the costs were CAN $\$ 51,000$ ( $€ 30,000$; benefit of 2.43 QALYs) [6].

\section{Results}

The response rate (number of sent surveys divided by the number of received surveys) after 8 weeks was $69 \%$ for the trauma surgeons and $70 \%$ for the orthopaedic surgeons.

The responding trauma surgeons treated 593 intraarticular calcaneal fractures annually, with an average of 6.4 fractures per hospital per year. The responding orthopaedic surgeons saw 327 fractures, with an average of 3.5 fractures per hospital per year (Table 2).

According to data from the Dutch registries, 230,000 patients are treated for any type of fracture of the skeletal system at emergency departments annually in the Netherlands (http://www.veiligheid.nl). Calcaneal fractures do not represent a distinct group in this database.

The estimated number of hospital admissions of patients with any type of fracture was 59,194, of which, 486 patients had an intra- or extra-articular calcaneal fracture (http://www.prismant.nl). These data imply that $0.8 \%$ of all patients with a fracture admitted to the hospital were admitted due to a calcaneal fracture.

Table 2 Estimated numbers of fractures seen annually by trauma and orthopaedic surgeons

\begin{tabular}{lll}
\hline Number of fractures & \multicolumn{2}{l}{ Number of centres in the Netherlands } \\
\cline { 2 - 3 } & Trauma surgeons & Orthopaedic surgeons \\
\hline None & 30 & 35 \\
$1-2$ & 3 & 12 \\
$3-5$ & 12 & 25 \\
$6-10$ & 28 & 17 \\
$11-15$ & 9 & 5 \\
$16-20$ & 7 & 1 \\
More than 20 & 3 & 0 \\
\hline
\end{tabular}

The application of one or more fracture classification systems was reported by $29 \%$ of the responding trauma and orthopaedic surgeons. The Sanders computed tomography classification was used in $37 \%$ of these cases, the EssexLopresti conventional radiographic classification in $32 \%$, the Zwipp computed tomography classification in $25 \%$, the Eastwood-Atkins computed tomography classification in $5 \%$ and the classification by Rowe in $1 \%$.

The majority of patients were treated with ORIF (46\%), conservatively $(39 \%)$ or percutaneously according to Forgon and Zadravecz (10\%), as shown in Table 3. Large differences exist in the number of patients treated using these three most used techniques per province (Fig. 1). The definite use of bone grafts in the ORIF group was reported by $20 \%$ of respondents, a total of $42 \%$ used grafting when deemed necessary and $38 \%$ did not use bone grafts at all. Five different types of calcaneal plates were used in the Netherlands in the ORIF group (Synthes AO Plate, Biomet, AO cervical H-plate, New Deal and Stryker) and two different types of fixation in the percutaneous group (cannulated screws and Kirschner wires).

Patients remained non-weight bearing for a mean period of 9 weeks (range 0 to 12 weeks; $\mathrm{SD}=2$ weeks). Seven percent $(7 \%)$ of the respondents used one or more standardised outcome scores; the AOFAS hindfoot score (47\%), the Creighton-Nebraska score (21\%), the Maryland Foot Score (16\%) and the Short Form-36 (16\%).

The reported rate of superficial wound infections was $16 \%$. Lower rates were reported for foot compartment syndrome, wound dehiscence and deep infectious complications (Table 4). Seventy-two of the responding trauma and orthopaedic surgeons reported the performance of a late arthrodesis in 125 patients annually with persisting complaints after an intra-articular fracture. These respondents treated a total of 603 fractures combined annually, giving an annual arthrodesis rate of $21 \%$. Of all respondents, 151 surgeons, treating 606 fractures annually, estimated the return to work in 459 patients $(76 \%)$.

In this sample of 920 patients, $60 \%(n=558)$ were treated operatively and $40 \%(n=362)$ non-operatively. The Canadian data indicated that the average cost for these

Table 3 Number of patients treated per treatment modality by the responding orthopaedic and trauma surgeons

\begin{tabular}{lll}
\hline Treatment modality & Number of patients & $\%$ \\
\hline Manual reduction & 6 & 1 \\
Primary arthrodesis & 8 & 1 \\
Essex-Lopresti manoeuvre & 30 & 3 \\
Forgon-Zadravecz distraction & 94 & 10 \\
Conservative & 356 & 39 \\
ORIF & 426 & 46 \\
Total & 920 & 100 \\
\hline
\end{tabular}




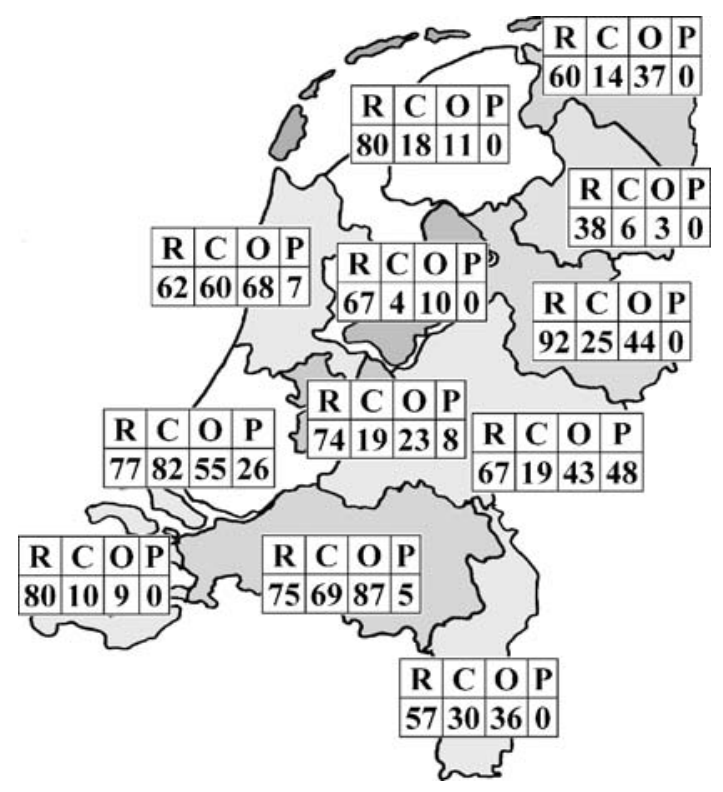

Fig. 1 Response rates and the number of patients treated using the three most frequently applied modalities per province in the Netherlands. $R=$ response rate in percentage; $C=$ absolute number of patients treated conservatively; $O=$ absolute number of patients treated using ORIF; $P=$ absolute number of patients treated percutaneously, as described by Forgon and Zadravecz

patients were CAN\$32,000 (€19,000) and CAN\$51,000 $(€ 30,000)$ for these groups, respectively. Therefore, the annual total costs for these 920 patients with intra-articular calcaneal fractures approximated $€ 21,462,000$. Assuming that the relative numbers of patients treated operatively and non-operatively for the $30 \%$ of non-respondents equals that of the respondents, the total annual cost for intra-articular calcaneal fractures in the Netherlands as a whole would be $\sim € 30,660,000$.

\section{Discussion}

This study was initiated to assess the incidence and the socio-economic cost of intra-articular calcaneal fractures in the Netherlands and to make an inventory of management approaches. In total, 920 fractures were treated by the

Table 4 Number of complications after intra-articular calcaneal fracture treatment

\begin{tabular}{lll}
\hline Complication & Number of patients & $\%$ \\
\hline Foot compartment syndrome & 14 & 2 \\
Wound dehiscence & 52 & $9^{*}$ \\
Superficial infection & 90 & $16^{*}$ \\
Deep infection & 13 & $2 *$ \\
\hline
\end{tabular}

Percentages with an asterisk $(*)$ are calculated for operated fractures only respondents, representing $0.4 \%$ of all fractures seen at the emergency departments. The annual socio-economic cost was estimated to be around $€ 21.5-30.7$ million.

The overall response rate of this study was $69 \%$, representing an above average response. A meta-analysis on 68 survey response rates showed that physicians have a mean response rate of $54 \pm 17 \%$ [2]. The influence of nonresponse bias was, therefore, low.

The 920 fractures found in this survey represent $0.4 \%$ of all fractures seen in the emergency departments. Adjusting for $30 \%$ of non-responders, the intra-articular calcaneal fracture incidence is $0.57 \%$. This is below the presumed incidence of $2 \%[16,20]$. It is unclear whether the latter percentage includes extra-articular calcaneal fractures. If the incidence of calcaneal fractures from our study is adjusted to include non-responders $(30 \%)$ and extra-articular fractures $(25 \%)$, the overall incidence of calcaneal fractures would be $0.75 \%$. The latter approximates the $0.8 \%$ incidence calculated by dividing the number of patients with a calcaneal fracture admitted $(n=486)$ by the total number of patients with any type of fracture admitted to the hospital $(n=59,194)$ (http://www.prismant.nl).

Few respondents used classifications $(29 \%)$ or outcome scoring (7\%) systems. The classifications used most frequently were the Sanders computed tomography classification and the Essex-Lopresti classification for plain radiography. Both systems have previously been shown to be of prognostic value, or showed a trend towards this, which indicates that these classification systems may be used when determining prognosis [9]. An explanation for the limited use of a classification and an outcome scoring system might be that these tools are mainly designed for research purposes. It must be noted that, of the responding academic hospitals, $100 \%$ used one or more classification systems and over $70 \%$ applied an outcome scoring system. In most of the academic hospitals, research is being conducted concerning calcaneal fractures.

In total, $95 \%$ of intra-articular calcaneal fractures were treated with ORIF, conservative treatment and percutaneous distraction in the Netherlands, according to Forgon and Zadravecz.

A secondary arthrodesis rate of $21 \%$ was calculated for all treatment modalities combined, which lies within the reported range for conservatively treated patients (16-30\%) $[9,10]$ and at the upper end of the reported rates for surgically treated patients $(1-22 \%)[1,9]$. The variation in arthrodesis rates in surgically treated patients can be explained by the small number of patients in some studies and treatment variation in specialised centres [1].

The rate of infectious complications in the survey, $16 \%$ superficial and $2 \%$ deep infections, is similar to complication rates reported in a study by Howard et al., in which a superficial wound infection was reported in $16 \%$ and a deep 
infection in $5 \%$ of patients, mainly secondary to a superficial infection [17].

Calculation of the socio-economic cost is based upon a study using Canadian health care parameters [9], which limits the interpretation of the Dutch socio-economic cost calculation. In Canada, only patients with proper insurance receive workers' compensation. Multiple studies indicated that patients receiving this workers' compensation have poorer outcome compared with patients not compensated $[8,9,15]$. In the Netherlands, every patient is compensated for sickness leave for a full year before procedures are started for a disability allowance. The return to work rate of $76 \%$ is in accordance with estimates in the literature [5]. The higher percentage of secondary arthrodeses, but comparable numbers of infectious complications, suggests an underestimation rather than an overestimation of the total costs calculated.

In the Canadian study, ORIF was used as the sole surgical technique [6]. Cost estimations for patients treated percutaneously are lacking; however, there are no indications that costs for patients treated with ORIF or percutaneous techniques will differ [14]. Therefore, costs for all Dutch patients treated operatively (ORIF, percutaneous treatment and primary arthrodeses) in the survey could be based upon the Canadian ORIF group costs.

Due to obvious differences between the Dutch and Canadian health care systems, the calculated socio-economic cost (€21.5-30.7 million) should be interpreted as an estimation for the Netherlands.

\section{Conclusions}

The total number of intra-articular calcaneal fractures in this survey comprises $0.4 \%$ of all fractures seen in the emergency departments in the Netherlands and the total Dutch incidence is estimated at $0.8 \%$.

For the treatment of intra-articular calcaneal fractures, surgeons in the Netherlands prefer the use of open reduction and internal fixation (ORIF) over conservative and percutaneous treatment. Bone grafting is only infrequently used and the non-weight bearing period is 9 weeks on average. The Sanders and Essex-Lopresti fracture classifications are favoured over other classification systems. Outcomescoring systems are infrequently applied. The Dutch annual socio-economic cost of calcaneal fractures is estimated to be in the range $€ 21.5-30.7$ million.

Acknowledgements The authors wish to thank Mr. J. T. H. M. Schepers for his assistance in the layout and distribution of the survey, and are indebted to Drs. I. B. Schipper and L. M. M. Vogels for their valuable contribution to the construction of the survey.

\section{References}

1. AO Publishing (2004) Intraarticular calcaneal fractures; operative management. Orthop Trauma Dir 2:9-16

2. Asch DA, Jedrziewski MK, Christakis NA (1997) Response rates to mail surveys published in medical journals. J Clin Epidemiol 50:1129-1136

3. Atkins RM, Allen PE, Livingstone JA (2001) Demographic features of intra-articular fractures of the calcaneum. Foot Ankle Surg 7:77-84

4. Bajammal S, Tornetta P 3rd, Sanders D, Bhandari M (2005) Displaced intra-articular calcaneal fractures. J Orthop Trauma 19:360-364

5. Barei DP, Bellabarba C, Sangeorzan BJ, Benirschke SK (2002) Fractures of the calcaneus. Orthop Clin North Am 33:263-285

6. Brauer CA, Manns BJ, Ko M, Donaldson C, Buckley R (2005) An economic evaluation of operative compared with nonoperative management of displaced intra-articular calcaneal fractures. J Bone Joint Surg Am 87:2741-2749

7. Bremner AE, Warrick CK (1951) Fractures of the calcaneus. J Facult Radiol 2:235-241

8. Buch BD, Myerson MS, Miller SD (1996) Primary subtalar arthrodesis for the treatment of comminuted calcaneal fractures. Foot Ankle Int 17:61-70

9. Buckley R, Tough S, McCormack R, Pate G, Leighton R, Petrie D, Galpin R (2002) Operative compared with nonoperative treatment of displaced intra-articular calcaneal fractures: a prospective, randomized, controlled multicenter trial. J Bone Joint Surg Am 84-A:1733-1744

10. Crosby LA, Fitzgibbons T (1993) Intraarticular calcaneal fractures. Results of closed treatment. Clin Orthop Relat Res 290:47-54

11. Edwards P, Roberts I, Clarke M, DiGuiseppi C, Pratap S, Wentz R, Kwan I (2002) Increasing response rates to postal questionnaires: systematic review. BMJ 324:1183

12. Essex-Lopresti P (1952) The mechanism, reduction technique, and results in fractures of the os calcis. Br J Surg 39:395-419

13. Forgon M (1993) Closed reduction and percutaneous osteosynthesis: technique and results in 265 calcaneal fractures. In: Tscherne H, Schatzker J (eds) Major fractures of the pilon, the talus, and the calcaneus. Springer, New York, pp 207-213

14. Frohlich P, Zakupszky Z, Csomor L (1999) Experiences with closed screw placement in intra-articular fractures of the calcaneus. Surgical technique and outcome (in German). Unfallchirurg 102:359-364

15. Geel CW, Flemister AS Jr. (2001) Standardized treatment of intraarticular calcaneal fractures using an oblique lateral incision and no bone graft. J Trauma 50:1083-1089

16. Hall MC, Pennal GF (1960) Primary subtalar arthrodesis in the treatment of severe fractures of the calcaneum. J Bone Joint Surg $\mathrm{Br}$ 42-B:336-343

17. Howard JL, Buckley R, McCormack R, Pate G, Leighton R, Petrie D, Galpin R (2003) Complications following management of displaced intra-articular calcaneal fractures: a prospective randomized trial comparing open reduction internal fixation with nonoperative management. J Orthop Trauma 17:241-249

18. Johnson T, Owens L (2003) Survey response rate reporting in the professional literature. Presented at the 58th Annual Meeting of the American Association for Public Opinion Research, Nashville, Tennessee, May 2003

19. Pozo JL, Kirwan EO, Jackson AM (1984) The long-term results of conservative management of severely displaced fractures of the calcaneus. J Bone Joint Surg Br 66:386-390

20. Slatis P, Kiviluoto O, Santavirta S, Laasonen EM (1979) Fractures of the calcaneum. J Trauma 19:939-943

21. Soeur R, Remy R (1975) Fractures of the calcaneus with displacement of the thalamic portion. J Bone Joint Surg Br 57:413-421 